Universität Bielefeld Faculty of Business Administration and Economics

Working Papers in Economics and Management

No. 03-2013

February 2013

\title{
Trade, Education, and the Shrinking Middle Class
}

\author{
Emily Blanchard
}

Gerald Willmann 


\title{
Trade, Education, and The Shrinking Middle Class*
}

\author{
Emily Blanchard ${ }^{\dagger} \quad$ Gerald Willmann ${ }^{\ddagger}$
}

February 12, 2013

\begin{abstract}
We develop a new model of trade in which educational institutions drive comparative advantage and determine the distribution of human capital within and across countries. Our framework exploits a multiplicity of sectors and the continuous support of human capital choices to demonstrate that freer trade can induce crowding out of the middle occupations towards the skill acquisition extremes in one country, and simultaneous expansion of middle-income industries in another. Individual gains from trade may be non-monotonic in workers' ability, and middle ability agents can lose the most from trade liberalization. Comparing trade and education policy, we find that targeted education subsidies are more effective than tariffs as a means to preserve "middle class" jobs, while uniform educational subsidies have no effect.
\end{abstract}

Keywords: Trade and Education Policy, Skill Acquisition, Education, Income Distribution

JEL Classifications: F11, F13, F15, F16

\footnotetext{
*We are grateful to John McLaren, Andrés Rodríguez-Clare, Sarah Turner, and seminar participants at Kiel, Trinity University, Copenhagen Business School, and the University of Virginia, St. Louis Federal Reserve, 2008 NBER ITI Summer Institute, 2009 AEA meetings, 2009 Midwest International Economics Group, and 2009 Belgian Trade Workshop for thoughtful suggestions. Maarten Goos and Alan Manning generously shared their figures, which help motivate the model.

$\dagger$ Tuck School of Business at Dartmouth College; emily.blanchard@tuck.dartmouth.edu.

${ }_{\ddagger}^{\ddagger}$ Department of Economics, Bielefeld University and IfW Kiel; gwillmann@wiwi.uni-bielefeld.de.
} 


\section{Introduction}

Politicians tend to portray education as a universal panacea for rising income inequality and perceived competition with foreign exporters - a cure-all with which the industrialized world will be able to maintain a thriving middle class and ever-greater standards of living. ${ }^{1}$ At the same time, popular sentiment reflects growing unease with individuals' economic prospects and a perception that even a solid education no longer guarantees a good job, secure career path, or membership in the middle class. ${ }^{2}$ In this paper, we explore the source of the disconnect between political rhetoric and public perception - the simple realization that workers' responses to education are not uniform: while many workers can and will optimally respond to global competition by moving up the skill acquisition ladder into sophisticated export-sectors, others will self select downward as former mid-skill jobs are lost to foreign competition. To structure thinking, we first develop a novel model of how trade and educational institutions interact to determine individuals' skill acquisition decisions, which we then use to examine the roles of trade and education policies.

The modelling strategy we propose is in contrast to much of the existing work in the trade literature, which restricts models with endogenous human capital decisions to a two good (and often binary skill choice) framework. In canonical models, the

\footnotetext{
${ }^{1}$ The U.S. Congressional Record is rich with such statements; for example, "We do this by investing in and reforming education and job training so that all Americans have the skills necessary to compete in the global economy" - President Barak Obama, February 14, 2011 (S679). The rhetoric is similar in Europe where the EU commissioner for education, Androulla Vassiliou states on her website that "Improvements in education [...] are needed to help Europe compete globally and equip the young for today's job market ..."

${ }^{2}$ A recent report by the Pew Research Pew Research Center (2012) found that " $85 \%$ of selfdescribed middle-class adults say it is more difficult now than it was a decade ago for middle-class people to maintain their standard of living." (Fewer, Poorer, Gloomier, pg 1) At the same time, the fraction of respondents reporting that a college education was important requirement for middle class membership fell to $37 \%$, from $46 \%$ in 1991.
} 
opening up to trade will induce either skill upgrading (in a country with comparative advantage in skill intensive products) or skill downgrading (in countries with comparative advantage in 'basic' goods) through customary Stolper-Samuelson forces, but not both. A key prediction stemming from these models is immediate and unambiguous: in developed countries (which presumably hold comparative advantage in skill intensive goods), freer trade will induce workers to increase education and shift to higher skill, export-oriented sectors. Conversely, in countries with comparative advantage in less skill intensive goods (e.g. most developing countries), freer trade would increase the relative demand for unskilled workers and thus reduce workers' incentives to acquire human capital. Terms of trade changes, from any source, would induce similarly monotonic responses in skill acquisition.

Although analytically parsimonious, such a simple binary approach clearly oversimplifies the process of skill acquisition. Not only are the implications for education policy implausibly stark, the economic prediction denies an important empirical regularity: that within countries freer trade causes some workers to 'sort down' — often into low-skill menial jobs — while others simultaneously 'sort up' into higher skill jobs. A series of important recent studies find evidence of both job and wage polarization in developed countries. Goos and Manning (2007) demonstrate a hollowing out of middle class employment in the United Kingdom between 1979 and 1999. Figure 1, reproduced with permission below, shows job growth at both the bottom and top two 'job quality' deciles, with a simultaneous reduction in employment for the occupations in between. ${ }^{3}$ Autor, Levy, and Murnane (2003) and Autor, Katz, and Kearney (2006) document similar findings for both wages and employment in the United States, while Falvay, Greenaway, and Silva (2010) find the same trend in Portugal. ${ }^{4}$ On the oppo-

\footnotetext{
${ }^{3}$ Job quality is proxied by median wage in each three-digit occupation code (SOC90) in 1979, which the authors identify as reasonable single-index model of skill, following Card and Lemiuex (1996).

${ }^{4}$ Broda and Romalis (2009) provide further evidence of a middle-class real wage decline relative
} 
site side, the two most comprehensive studies to date, Ravallion (2009) and a special report in The Economist magazine,${ }^{5}$ document a dramatic expansion of the middle class incomes in the developing world over the last decades, where workers are moving $u p$ the lower rungs of the skill acquisition ladder, substituting for their rich world counterparts.

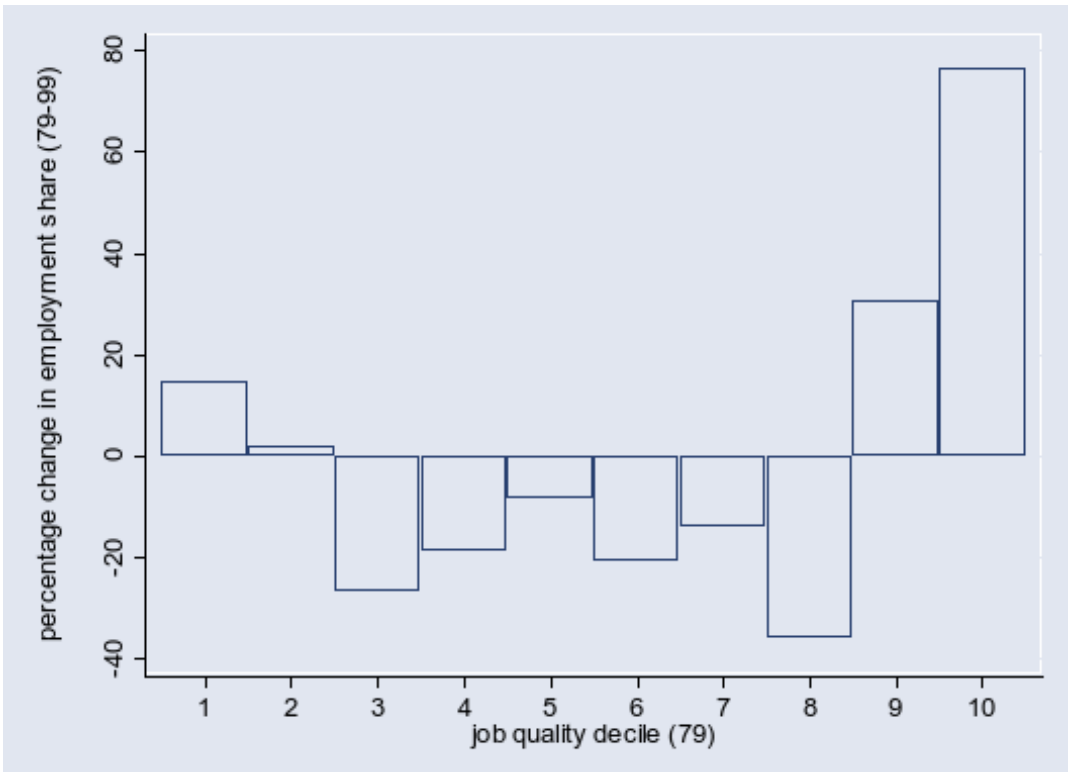

Figure 1: Non-Monotonic Changes in Employment (Goos and Manning (2007))

If economists are to contribute on the issues surrounding education and globalization, we thus must necessarily begin by shifting away from binary two-good models. This paper does so by developing a new model that helps us understand how educational institutions and trade interact. Our formal framework features a continuum of heterogeneous agents who differ in their inherent ability to acquire skills through to low and high income groups through relative prices of consumption bundles under non-homothetic preferences: prices for goods bought by low-income families have fallen more than prices for consumption bundles for middle-income families; high-income groups have seen the slowest price declines, but their nominal wages have also risen the fastest.

5 "Burgeoning Bourgeoisie: A special Report on the New Middle Classes in Emerging Markets," February 14, 2009 
education. Agents choose among a continuum of occupational sectors (or tasks), each of which requires a unique set of skills for employment. Wages are determined by sectoral technology and intermediate good (task) prices - and thus by trade openness - while the cost of human capital acquisition is determined by both individual level characteristics and the country-specific structure of educational institutions and policies. Faced with the resulting incentive structure, agents of different inherent ability levels self-select into sectors by investing in the corresponding human capital, following a familiar assortative matching process based on the complementarity between innate ability and skill acquisition. ${ }^{6}$

Comparative advantage in our model is driven by international differences in educational institutions and the resulting differences in the costs of skill acquisition. Trade liberalization leads to a remapping of agents to sectors, as would changes in trading partners' technologies, trade costs, or educational institutions that influence the cost of skill acquisition. The resulting shift in the demographics of skill composition can take different forms. One plausible and particularly salient scenario in line with the earlier diagram is the crowding out of the middle class towards the skill acquisition extremes, which can be brought about by increasing foreign competition in medium-level intermediate goods or tasks. In response to such competition, some moderate ability agents will invest in greater human capital, while others will optimally invest less. More generally, we find that only in special cases would all agents' human capital decisions respond monotonically to changes abroad. While the aggregate gains from trade are positive in our set-up, the distributional consequences are generally complex and non-monotonic.

\footnotetext{
${ }^{6}$ The basic mechanics of our assortative mapping mechanism, long used in the broader literature, has been introduced in the trade context by Grossman and Maggi (2000). (See Milgrom and Roberts (1990) for a canonical application outside the trade literature.) Supermodularity/complementarity has been used subsequently in trade models by Antras, Garicano, and Rossi-Hansberg (2006), Nocke and Yeaple (2008), Costinot and Vogel (2010), and Mrazova and Neary (2012), among many others.
} 
Turning to policy analysis, we use the model to shed light on the potential differential impact of strengthening educational institutions versus trade protection. In general, government subsidies to education or similar institutional improvements that decrease the cost of skill acquisition will influence workers' human capital decisions and thus the pattern of comparative advantage and trade. Targeted trade protection can have a similar effect by buoying the wages in import-sensitive sectors relative to the rest of the economy, but the concomitant consumption distortions imposed by tariffs make education policy a more efficient policy tool for redistributing income and human capital. We find additionally that if the government has an explicit preference for a 'strong middle class', then uniform educational investment will serve little purpose. Instead, educational incentives would need to induce skill upgrading among the least able workers through more pronounced subsidization and reform at the most basic educational levels, while allowing for skill downgrading (or at least slower upgrading) among the highly educated elite.

Our approach in this paper is motivated foremost by the empirical findings discussed at the outset of the paper. As noted earlier, Autor, Levy, and Murnane (2003), Autor, Katz, and Kearney (2006), Goos and Manning (2007), and Falvay, Greenaway, and Silva (2010) document both wage and employment polarization in much of the industrialized world. While several authors have posited alternative models to explain the phenomenon through routinization, skill-biased technological change, or shifting consumer preferences - including Autor, Katz, and Kearney (2006) and Autor and Dorn (2013) — we submit that the fall in demand for mid-skill workers in the industrialized world is unlikely a story of technological change alone, but is (also) crucially tied to countries' comparative advantage, relative educational structures, and globalization in a wide sense (trade, offshoring, outsourcing) ${ }^{7}$

In modeling occupational output as tradable tasks, we recall Grossman and

\footnotetext{
${ }^{7}$ For earlier work suggestive of a demand-side story, see e.g. Katz and Murphy (1992), Bound and Johnson (1992), Juhn, Murphy, and Pierce (1993), and Berman, Bound, and Griliches (1999).
} 
Rossi-Hansberg (2008), who propose a two-sector model of trade in tasks and focus on the welfare effects of outsourcing those tasks that can be carried out abroad. Also related is the recent work by Jung and Mercenier (2008), who propose a model that features outsourcing of intermediates and endogenous human capital decisions. Several key aspects of their model make it two sector set-up in practice, however; as a consequence, skill upgrading in their framework is necessarily one-directional as in the more traditional trade literature.

From a more technical standpoint, our continuum framework is reminiscent of Dornbusch, Fischer, and Samuelson (1977). More recently, Yeaple (2005), Ohnsorge and Trefler (2007), Anderson (2011), and Helpman, Isthoki, and Redding (2010) also incorporate heterogeneous agent matching features into a continuum setting which, as here, can generate non-monotonic welfare consequences of trade. Closely related is the recent paper by Costinot and Vogel (2010), which features an assortative matching mechanism similar to our own to emphasize the potential for income polarization in response to trade. None of these models endogenize workers' human capital decisions, however. And because workers' skill levels are taken as given, these models are not equipped to study the potential role of educational institutions in shaping the interaction between trade and human capital, which is precisely the goal here.

The remainder of the paper is structured as follows. In Section 2, we introduce the model, analyze the effects of trade under the small country assumption, and give the equilibrium conditions for the large country case. Section 3 adopts functional forms to illustrate further the inner workings of the model and to present the equilibrium characteristics of a two country case with non-monotonic skill change. In Section 4 we turn to the model's policy implications by introducing the possibility of education subsidies and tariffs. Section 5 concludes. 


\section{The Model}

The Home country is populated by a continuum of heterogeneous agents with unit mass. Individual agents differ in their inherent ability level (or equivalently, ability to learn), $a$, assumed to be distributed continuously over the unit interval with cumulative distribution function $F(a)$ and corresponding density function $f(a)$. Every agent is endowed with a single unit of labor, which is supplied inelastically to the labor market.

The economy produces a single homogeneous final good, $Y$, using constant returns to scale technology and a continuum of intermediate tasks (or products) $j \in$ $[0,1]$, where $j$ may be thought of as an index of the intermediate sectors' technological sophistication. Each intermediate sector uses a specialized type of labor and produces under constant returns and perfect competition. Productivity is assumed to be the same for all workers of an acquired skill type, regardless of the agent's inherent ability. ${ }^{8}$ The final good serves as numeraire with price denoted by $p \equiv 1$. Finally, we choose units so that the real wage in sector $j$, measured in units of the final good $Y$, is simply the trading price of the relevant intermediate good/task and is denoted by $w(j)$.

In order to supply one unit of specialized labor of type $j$, agents have to acquire the required skills through training and education. The cost (in units of the numeraire, $Y)$ to agent $a \in[0,1]$ of acquiring the skills for a given sector $j \in[0,1]$ is described by the function $c(j, a)$, which is twice continuously differentiable in each argument. We assume that the cost of skill acquisition is increasing in the technological sophistication of the sector and decreasing in the ability level of the agent, and that the cost of

\footnotetext{
${ }^{8}$ Alternatively, one can build worker heterogeneity into productivity (and hence wages) rather than educational costs. The two approaches are isomorphic in terms of sorting of workers across sectors, though aggregate output would vary, of course, depending on whether ability is productive or not. We follow the approach chosen here as proves more parsimonious (and plausible) when we analyze education policy in a later section.
} 
skill acquisition is convex across sectors for every agent. Finally, the marginal cost of upgrading skills from one sector to the next is lower for high ability agents. This negative complementarity (or sub-modularity) of $a$ and $j$ in the education cost function reflected in the negative cross partial derivative will ensure assortative matching of higher ability individuals to higher education levels. Formally, we make the following assumption on the cost of skill acquisition:

\section{Assumption 1}

$$
\begin{aligned}
\frac{\partial c(j, a)}{\partial j}>0, & \frac{\partial c(j, a)}{\partial a}<0 \\
\frac{\partial^{2} c(j, a)}{\partial j^{2}}>0, & \frac{\partial^{2} c(j, a)}{\partial j \partial a}<0 .
\end{aligned}
$$

Additionally, in the interest of tractability, we will consider the following simplification:

$$
\begin{aligned}
c(j, a) & \equiv h(a) g(j) \\
c^{*}(j, a) & \equiv h(a) g^{*}(j),
\end{aligned}
$$

where the functions $h(\cdot)$ and $g(\cdot)$ are twice continuously differentiable and nonnegative over the unit interval. Note that Assumption 1 implies that $h^{\prime}(a)<0$, $g^{\prime}(j)>0$ and $g^{\prime \prime}(j)>0$ for all $j \in[0,1]$.

Optimal Sorting and Production. Agents consume only the final good $Y$ with non-satiated preferences. Thus, when deciding which sector to enter, every agent $a$ chooses $j$ to maximize his net real wage, $w(j)-c(j, a)$. Taking the wage schedule as given, the first order condition for each individual's optimal human capital level is then:

$$
\frac{\partial c(j, a)}{\partial j}=\frac{d w(j)}{d j},
$$

Using superscript dots to denote derivatives with respect to $j$, the first order condition for agent $a$ 's optimal human capital decision/sectoral choice may be rewritten:

$$
\dot{c}(j, a)=\dot{w}(j)=\dot{g}(j) h(a) .
$$


The second order condition of the agents' maximization problem is:

$$
\ddot{w}(j) \leq \ddot{c}(j, a)
$$

that is, the wage schedule - exogenous in a small open economy and endogenous if the country is large or autarkic - must be less convex than the cost function. Provided the second order condition is satisfied globally (i.e. for any $j \in[0,1]$ ), then in $\{j, a\}$ space, $\dot{c}(j, a)$ crosses $\dot{w}(j)$ at most once from below for any given $a$, and (2.5) implicitly defines a unique critical value of $j$ for each agent. Rearranging (2.5) yeilds the following allocation (or self-sorting) of ability types to sectors:

$$
a(j) \equiv h^{-1}\left(\frac{\dot{w}(j)}{\dot{g}(j)}\right) .
$$

Note that the second inequality in Assumption 1 ensures that $h(\cdot)$ is invertible so that $a(j)$ is defined. When $a(j)$ is strictly monotonic, and thus itself invertible, we will denote the mapping of ability types to sectors by $j(a)$.

The assumptions made earlier ensure several important properties of the mapping function in (2.7). The third inequality of Assumption 1 ensures single crossing, so that agents map to sectors assortatively; ${ }^{9}$ the sorting function is strictly monotonic if the second order condition holds with strict inequality. Further, assuming that $h(\cdot), g(\cdot) \in C^{2}$ in $j$ implies that if $w(j)$ is continuously differentiable (twice continuously differentiable), then the mapping function $a(j)$ is itself continuous (continuously differentiable). Finally, if the wage schedule is twice continuously differentiable, $a^{\prime}(j)$ will be everywhere finite. To summarize formally:

Lemma 2.1 For a given strictly increasing wage schedule, $w(j)$ :

i) a(j) is non-decreasing (strictly increasing) in $j$ if $\ddot{w}(j) \leq \ddot{c}(j, a)(\ddot{w}(j)<\ddot{c}(j, a))$ $\forall j, a$.

\footnotetext{
${ }^{9}$ Note that $\dot{w}(j)>0$ is a necessary condition for positive production in sector $j$.
} 
ii) $a(j)$ is continuous (continuously differentiable) in $j$ if $w(j) \in C^{1}\left(C^{2}\right)$.

iii) $a^{\prime}(j)$ is finite for all $j$ if $w(j) \in C^{2}$.

Proof: See appendix.

Notice that the derivative of the mapping function, $a^{\prime}(j)$, indicates the density of agents in any given sector $j$. Thus, zero employment in a range of sectors would be represented by a flat segment of the $a(j)$ mapping function in $\{j, a\}$ space. Part $i$ ) of the preceding lemma rules out the possibility of empty sectors if the wage schedule is everywhere less convex than the cost schedule for all agents and all sectors. By similar logic, a potential mass point in the distribution of agents across sectors would be represented by an infinite derivative of the $a(j)$ function. Part $i i i)$ indicates that continuity in the $\ddot{w}(j)$ schedule is sufficient to rule out the possibility of mass points, thus ensuring that the mapping of agents to sectors is strictly assortive: higher ability agents self select into strictly higher $j$ occupations.

The sorting mechanism is easliy illustrated by a pair of simple graphs. Figure 2 depicts the optimal sorting of agents to sectors as a function of the local wage schedule and the cost of education for each agent. ${ }^{10}$ Panel A illustrates agents' optimal sectoral choice according to the first order condition in (2.5); Panel B depicts the resulting mapping of agents to occupational sectors.

It is now straightforward to evaluate the impact of an exogenous change in the domestic price/wage schedule on the equilibrium skill distribution. Suppose there is across the board wage compression, for instance in a small open economy following a shift in the terms of trade. In Panel $\mathrm{A}$, the derivative wage schedule, $\dot{w}(j)$, shifts

\footnotetext{
${ }^{10} \mathrm{We}$ suppose here for the sake of simplicity that the wage schedule is such that for every $a$ there exists a unique optimal sectoral choice $j$, as depicted. In principle, the derivative wage schedule could cross a given derivative cost function several times. In that instance, the globally optimal $j(a)$ would be an element (or subset) of the critical values defined by (2.7) for which the second order condition is also satisfied.
} 

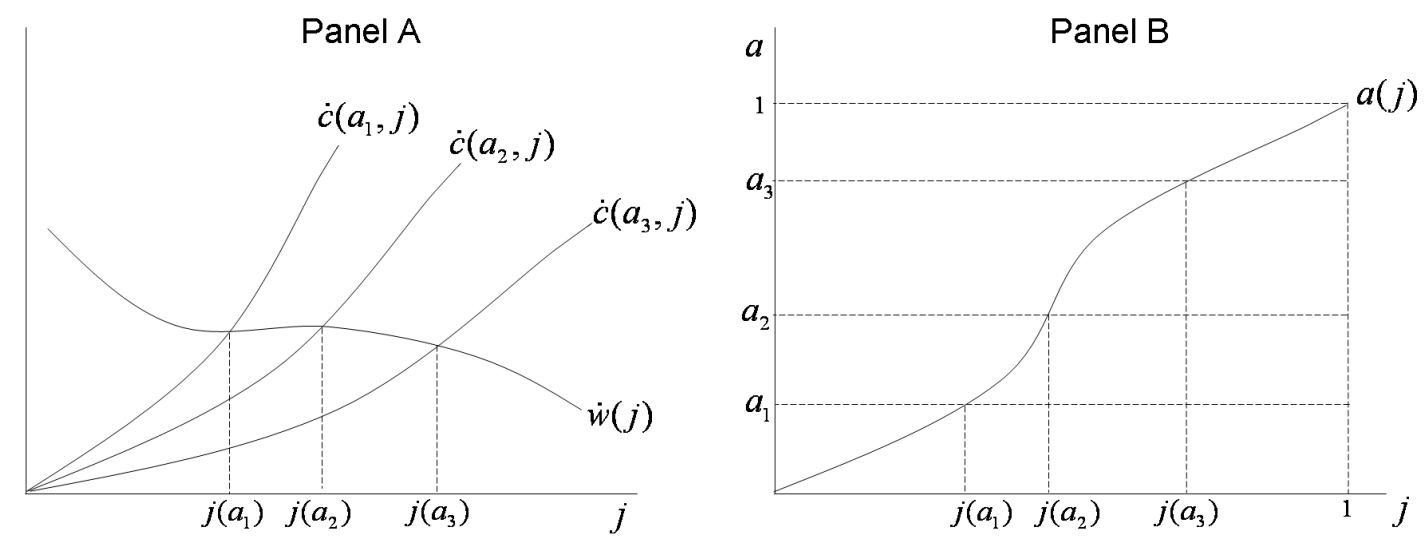

Figure 2: Optimal Sorting

down and every agent will choose a lower $j$ occupation, or 'sort down' in response to the decreased wage premia for skill upgrading. ${ }^{11}$ Conversely, if we suppose instead a universal exaggeration of skill premia - so that the wage schedule is everywhere steeper than before $(\dot{w}(j)$ shifts up), agents will choose higher skilled occupations, or 'sort up'. It is worth noting explicitly that for any vertical shift in the wage schedule for which the derivative wage schedule, $\dot{w}(j)$, remains unchanged, there would be no impact on agents' occupational choices or aggregate output. It is not the absolute level of wages, but rather the relative wage differences - reflected in the derivative wage schedule - that determine sorting. (Welfare is another matter.) The following proposition formalizes, assuming a parsimonious case of unique single crossing for all agents:

Proposition 2.1 For any two wage schedules $w_{1}(j)$ and $w_{2}(j)$ :

i) if $\dot{w}_{1}\left(j_{1}(a)\right)=\dot{w}_{2}\left(j_{1}(a)\right)$, then agent a would choose the same sector under either wage schedule: $j_{1}(a)=j_{2}(a)$;

\footnotetext{
${ }^{11}$ In a dynamic framework in which agents cannot recoup the costs of over-education (in essence reselling their degrees), we would expect agents to remain in their same jobs or, if $\dot{w}(j)<0$ in the relevant region, to shift into lower-skill work for which they are then overqualified.
} 
ii) if $\dot{w}_{1}\left(j_{1}(a)\right)>\dot{w}_{2}\left(j_{1}(a)\right)$, then agent a would choose a higher sector under $w_{1}$ than under $w_{2}: j_{1}(a)>j_{2}(a)$;

iii) if $\dot{w}_{1}\left(j_{1}(a)\right)<\dot{w}_{2}\left(j_{1}(a)\right)$, then agent a would choose a lower sector under $w_{1}$ than under $w_{2}: j_{1}(a)<j_{2}(a)$.

Proof: The result is immediate from the definition of $a(j)$ in $(2.7)$.

Since we are interested in non-monotonic skill change - i.e. the simultaneous 'sorting up' and 'sorting down' of workers - note that the proposition directly implies the following:

Corollary 2.2 Non-monotonic skill change occurs if and only if there exists a pair of sectors $\left\{j_{l}, j_{h}\right\}$, each in the unit interval, such that $\dot{w}_{1}\left(j_{l}\right)<\dot{w}_{2}\left(j_{l}\right)$ and $\dot{w}_{1}\left(j_{h}\right)>$ $\dot{w}_{2}\left(j_{h}\right)$.

That is, non-monotonic skill change will occur if (and only if) the two marginal wage schedules cross at least once. ${ }^{12}$

Now that we have analyzed the sorting mechanism, we are in a position to close the model by defining appropriate equilibrium conditions. We will do so first for the case of a small open economy, before turning attention to the case of two large countries.

Equilibrium Conditions for a Small Open Economy. Under our simple oneto-one production function, the domestic supply schedule for intermediates is given by the labor allocation of workers across sectors. Thus, domestic output of a given

\footnotetext{
${ }^{12}$ The corollary continues to assume a case in which agents' second order condition holds globally, as stated in Proposition 2.1. For a more complex case in which there are multiple local solutions to the optimal sectoral choice problem for at least some agents, we cannot characterize the outcomes so simply. We do not find such technical possibilities particularly interesting or economically relevant, however.
} 
intermediate good $j \in[0,1]$ is simply the density of workers of each type in the population, multiplied by the density of worker types in each sector:

$$
y_{s}(j)=a^{\prime}(j) f(a(j)) .
$$

Notice that the supply of intermediates depends on both the wage schedule and the cost of skill acquisition, via the $a(j)$ mapping function.

Based on the total supply of intermediates, domestic output of the final good is given by $Y \equiv \psi(\vec{y})$, where $\psi(\cdot)$ denotes the constant returns technology used to produce the final good, $\vec{y}$ is used to describe the complete $y(j)$ schedule over $j \in[0,1]$, and each $y(j) \equiv y_{s}(j)+y_{t}(j)$ includes net imports of intermediate products, $y_{t}(j) .{ }^{13}$ We denote the total local unit factor demand for intermediate $j$ by $x(j) \equiv x_{j}(\vec{w}, 1){ }^{14}$ and note that in general it depends on the complete wage schedule.

The equilibrium conditions are then as follows. Full employment requires that every worker of every type is fully employed, i.e.:

$$
f(a)=j^{\prime}(a) y_{s}(j(a)) \quad \forall a \in[0,1]
$$

where the left hand side is labor supply of each worker type, and the right hand side defines equilibrium labor demand. ${ }^{15}$ Market clearing for each intermediate implies:

$$
y(j)=a^{\prime}(j) f(a(j))+y_{t}(j)=x(j) Y \quad \forall j \in[0,1] .
$$

The zero profit condition in aggregate good production requires total revenue to equal total factor payments so that:

$$
Y \equiv \psi(\vec{y})=\int_{0}^{1} w(j)\left[a^{\prime}(j) f(a(j))+y_{t}(j)\right] d j .
$$

\footnotetext{
${ }^{13} y_{t}(j)<0$ indicates a net export.

${ }^{14}$ Recall that constant returns to scale technology implies that conditional factor demand for each intermediate $j$ may be written $x_{j}^{T}(\vec{w}, Y)=x_{j}(\vec{w}, 1) Y \equiv \arg \min _{x_{j}} \vec{w} \cdot \vec{x}$ s.t. $\psi(\vec{x}) \geq Y$.

${ }^{15}$ Note that (2.9) implies that total employment in the economy across all types (and all sectors) maps to the unit population mass: $\int_{0}^{1} j^{\prime}(a) y_{s}(j(a)) d a=\int_{0}^{1} a^{\prime}(j) f(a(j)) d j=1$.
} 
Finally consumers' balanced budget condition requires that consumption expenditure on the final good equals workers' net income: ${ }^{16}$

$$
Y^{c}=\int_{0}^{1}[w(j(a))-c(a, j(a))] d a,
$$

where $Y^{c}$ denotes aggregate consumption of the final good. Any trade imbalance in intermediates is made up by shipments of the final good $Y .{ }^{17}$

For a small open economy, the system described by (2.9) - (2.12) pins down, for any exogenously given wage schedule, the equilibrium allocation of agents to occupational sectors, intermediate production levels and trade, as well as aggregate final good output and consumption.

Equilibrium Conditions for Large Economies. To endogenize the wage schedule when Home is large, we now introduce a second country, Foreign (variables denoted by $\left.{ }^{*}\right)$. Let Foreign mirror Home in all aspects except the educational cost structure: Foreign has the same unit mass of population with an identical ability distribution, the same non-satiated preferences and inelastic labor supply, and the same production technology for intermediates and the final good. We restrict attention to differences in educational institutions because this is the novel force driving comparative advantage, and ultimately the focus of this paper. ${ }^{18}$

Under autarky each economy is characterized by a system of equilibrium conditions analogous to equations (2.9) - (2.12) above. Solving these, together with the autarkic condition that trade is zero $\left(\vec{y}_{t}=\vec{y}_{t}^{*}=\overrightarrow{0}\right)$ yields the autarkic equilibrium

\footnotetext{
${ }^{16}$ Tariff revenue, if appropriate, would simply be added to the RHS of (2.12).

${ }^{17}$ If $Y$ is not tradeable, then balanced trade in intermediates requires: $\int_{0}^{1} w(j) y_{t}(j) d j=0$. (Moreover, if some intermediates are not traded in equilibrium (and $Y$ is non-tradeable), then the price of the numeraire in Home may differ from the world market price of $Y$.)

${ }^{18}$ Since technology differences are the main focus of the seminal work by Dornbusch, Fischer, and Samuelson (1977), we silence that well understood mechanism in the baseline version of our model. One could easily introduce different intermediate good productivity in an extension of the basic model to study the interaction between technology, educational institutions, and trade.
} 
wage schedules, which we denote by $w_{A}(j)$ for Home and $w_{A}^{*}(j)$ for Foreign. The equilibrium wage schedules in turn pin down all other variables of interest. Note that the first order condition ensures that the more convex (in $j$ ) is the local educational cost function, the steeper the autarkic equilibrium wage schedule (all else equal). This makes sense; to the extent that skill upgrading becomes increasingly expensive for more sophisticated (high $j$ ) sectors, the higher the incremental wage increases must be to induce workers to enter the most demanding occupations.

Under free trade, intermediates can be traded on the world market. The set of world market clearing conditions for intermediates is therefore:

$$
y(j)+y^{*}(j)=x(j) Y+x^{*}(j) Y^{*} \quad \forall j \in[0,1] .
$$

Additionally, we require that Home imports equal Foreign exports and vice-versa:

$$
y_{t}(j)=-y_{t}^{*}(j) \quad \forall j \in[0,1] .
$$

The remaining equilibrium conditions - full employment, zero profit, and balanced budget in (2.9), (2.11), and (2.12) respectively - are the same as before, for both Home and Foreign. Together, these equilibrium conditions jointly determine the unified free trade equilibrium wage schedule, which we denote by $w_{F T}(j)$. This wage schedule then pins down the allocation of workers across sectors (and thus the distribution of human capital within and across countries), the supply of intermediates, aggregate output, and consumption in each country, as well as the pattern of trade. Note that for any sectors in which only one country produces in equilibrium, the market clearing condition in (2.13) has a single term on the left hand side, so that only the producing country's educational cost structure will influence the wage directly.

In general, the market clearing conditions can be characterized by a differential equation of the wage schedule over $j$. Collapsing the system of intermediate market clearing conditions (of which there are an uncountable infinity) to a single differential equation yields enormous returns in model tractability: namely, equilibrium proper- 
ties can be summarized by the behavior of the wage schedule over $j \in[0,1]$ as above. At the same time, however, given that the equilibrium wage schedule is the solution to a differential equation of the third order, ${ }^{19}$ it should not be surprising that closed form solutions prove the exception rather than the rule.

The following section describes a case in which functional form assumptions offer clean analytical solutions in the general equilibrium model. In generating a set of closed form results, we highlight the role of educational institutions in determining both comparative advantage and the implications of trade for human capital acquisition, welfare, and income distribution within and across countries.

\section{A General Equilibrium Example}

In this section we provide a concrete example of our model that illustrates the simultaneous 'sorting up' and 'sorting down' of moderate ability agents and the negative welfare effects trade can have on the middle class. In order to make things tractable, we assume the following cost structures of education in home and foreign respectively: ${ }^{20}$

$$
\begin{aligned}
c[j, a] & =\frac{(1-a)}{a} * \frac{2 j^{2}}{5} \\
c^{*}[j, a] & =\frac{(1-a)}{a} * \frac{2 j^{3}}{3}
\end{aligned}
$$

The crucial feature of the above functional forms lies in the relative convexity

\footnotetext{
${ }^{19} y(j)$ depends on $a^{\prime}(j)$, which is a function of $\dot{w}(j)$ and $\ddot{w}(j)$ while $x(j)$ depends in general on the complete $w(j)$ schedule. Moreover, in a model with multiple final goods in which aggregate final goods output depends on its own price (i.e. $Y(p)$ ), the market clearing condition would instead be given by fourth order differential equation.

${ }^{20} \mathrm{We}$ adopt these functional forms primarily for analytical convenience, but also because they provide a 'nice' example in which both countries produce all goods. Appendix A1.2 explores modified functional forms designed to deliver a case of "limited diversification" in which one country is the exclusive producer of some goods in equilibrium.
} 
of both educational cost structures: the foreign educational cost structure is more convex in $j$ than is the domestic cost structure. Formally, we need the $\dot{c}^{*}(j, a)$ and $\dot{c}(j, a)$ functions to cross somewhere in the unit interval for at least some ability levels, $a \in[0,1]$. From a technical standpoint, the relative convexity of the Foreign cost structure ensures that Foreign will have comparative advantage in some middle $j$ sectors (necessary to generate non-monotonic skill change at Home following an opening to trade).

In practice, our assumption over the relative convexity of the cost schedules is consistent with a faster increase in the marginal cost of education abroad as individuals move up the skill acquisition ladder. We find this assumption particularly plausible in the context of many developing countries, where barriers to education make the shift from secondary to university to graduate education increasingly difficult relative to the industrialized world. Notice that it is only the relative costs of increasing education - i.e. the derivative of the wage schedules - that matter for sorting. Educational cost levels could be higher across the board in Foreign than in Home (which again seems likely in developing vs. developed country comparisons) without changing our results, apart from the quantitative welfare levels. ${ }^{21}$ We should note, too, that the model would easily permit alternative cost structures; we focus on this case because we are most interested in the potential for non-montonic skill change resulting from trade.

On the factor demand side, we assume Leontief production of the final good, thereby abstracting from possible substitution effects across intermediates. ${ }^{22}$ With

\footnotetext{
${ }^{21}$ To verify, simply add a constant to $\left.c^{*}[j, a]\right)$ and note that the sorting mechanism will be unchanged.

${ }^{22}$ More generally, substitution effects would dampen the magnitude of wage schedule changes, but would not overturn our qualitative findings; the technical benefit of the Leontief assumption is that $x_{j}(\vec{w}, 1)=1 \forall j$ so that the intermediates market clearing condition is only a second order differential equation (rather than third order) with a closed form solution.
} 
$\psi(\vec{y}) \equiv \min \left\{y_{0}, \ldots, y_{1}\right\}$, unit factor demand is simply one in each sector and country, regardless of the wage schedule; thus, $x(j) \equiv x_{j}(\vec{w}, 1)=x^{*}(j)=1$.

Following the solution procedure outlined in the previous section, we solve for the equilibrium wage schedules:

$$
\begin{aligned}
\dot{w}_{A} & =\frac{4(1-j)}{5}, \\
\dot{w}_{A}^{*} & =2 j-2 j^{2}, \\
\dot{w}_{F T} & =\frac{j\left(2+j-10 j^{2}\right)+\sqrt{j^{2}(4+j(4+4 j(121+20 j(-9+5 j))))}}{10 j},
\end{aligned}
$$

where we have used the boundary condition that the wage schedule must be flat at the upper end, $\dot{w}(1)=0$, to pin down the respective constants of integration. ${ }^{23}$ Figure 3

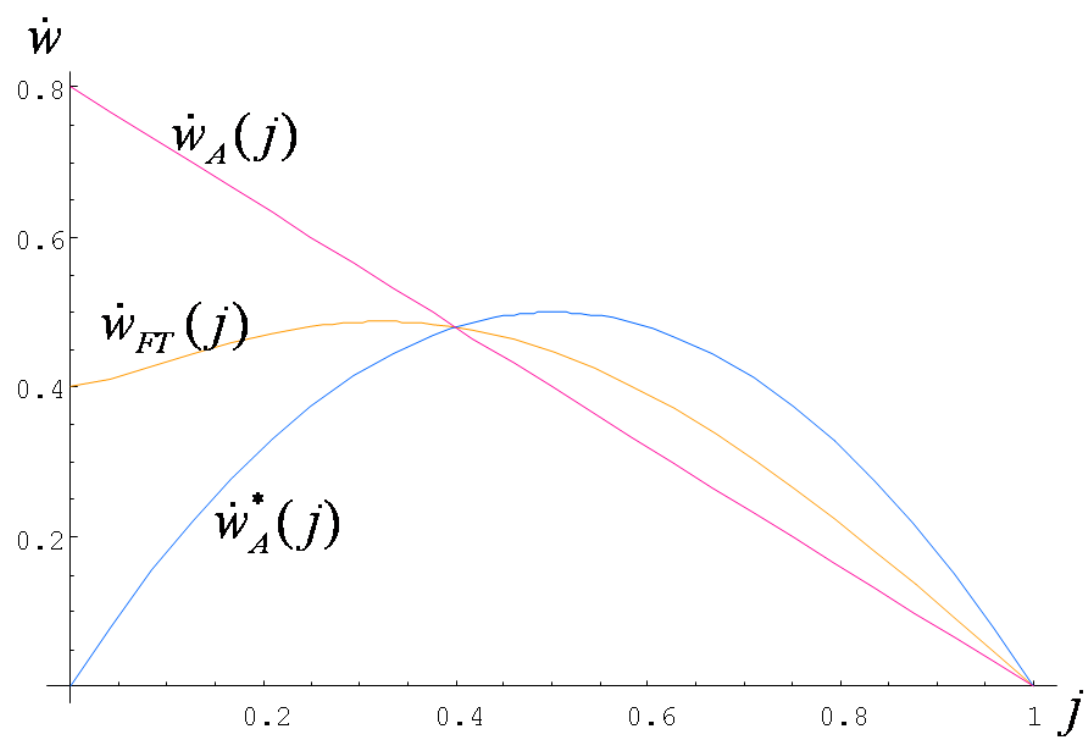

Figure 3: Slope of the Equilibrium Wage Schedules

shows that the slope of the equilibrium wage schedule under free trade lies between

\footnotetext{
${ }^{23}$ Violating this boundary condition (i.e. $\dot{w}(1)>0$ ) would imply a mass of workers clustered in $j=1$, which is a contradiction under the assumed Leontief production structure and the assumed cost function (for which $\dot{c} \rightarrow 0$ as $a \rightarrow 1$ ).
} 
those of the autarkic derivative wage schedules.

As discussed earlier, the equilibrium wage schedule implies a corresponding mapping of agents to sectors by ability level. In autarky, of course, the Leontief technology assumption implies a uniform density of workers across sectors:

$$
a_{A}(j)=a_{A}^{*}(j)=j .
$$

Under free trade the sectoral mappings take a polynomial form (we omit the functional forms here for brevity), depicted in Figure 4. Home's free trade $a(j)$ mapping is in pink, Foreign's free trade mapping is in dark blue, and the autarkic mapping schedules for both Home and Foreign are represented by the light blue diagonal on the 45 degree line.

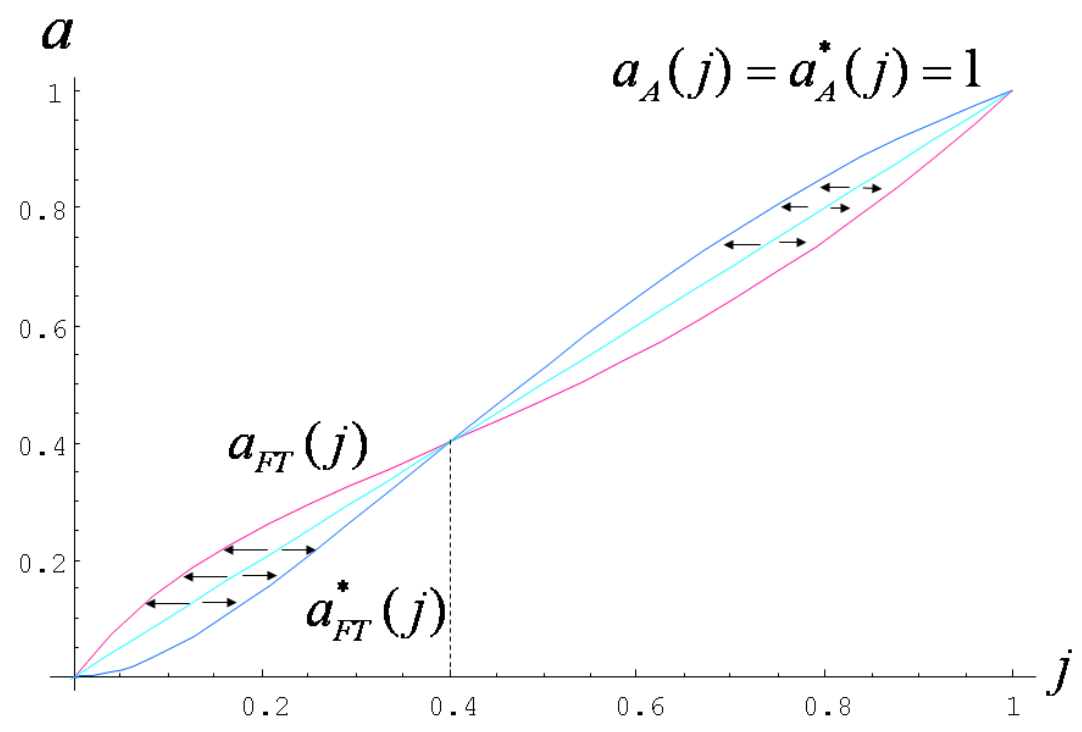

Figure 4: Mappings $a_{F T}(j)$ and $a_{F T}^{*}(j)$.

Figure 4 illustrates the reallocation of agents brought about by trade liberalization. Where the free trade mapping function lies above the diagonal, the corresponding ability level self-selects into a lower $j$ sector following liberalization; i.e. agents 
have sorted down. Where the free trade mapping function lies below the forty-five degree line, agents self select into higher $j$ occupations and human capital levels following the opening of trade. Overall, we see that in Home agents in the lower portion of the population distribution shift to lower $j$ sectors, while agents above $a=.4 \mathrm{shift}$ up, thus vacating the middle $j$ sectors toward the skill-acquisition extremes. The effects in Foreign are simply the reverse, since total labor supply of each factor must add to 2 under the Leontief final goods production structure.

Figure 5 depicts the resulting shift in employment density across sectors, which is equivalent to the supply of each intermediate output (given our assumption that $a \sim U[0,1])$. Again, note that the Leontief technology ensures uniform employment distribution in autarky. Under our assumptions in this example, trade pushes Home workers to the skill acquisition extremes - analogous to the empirical findings by Goos and Manning (2007) previously reproduced in Figure 1 - while 'middle class' employment flourishes in Foreign post liberalization.

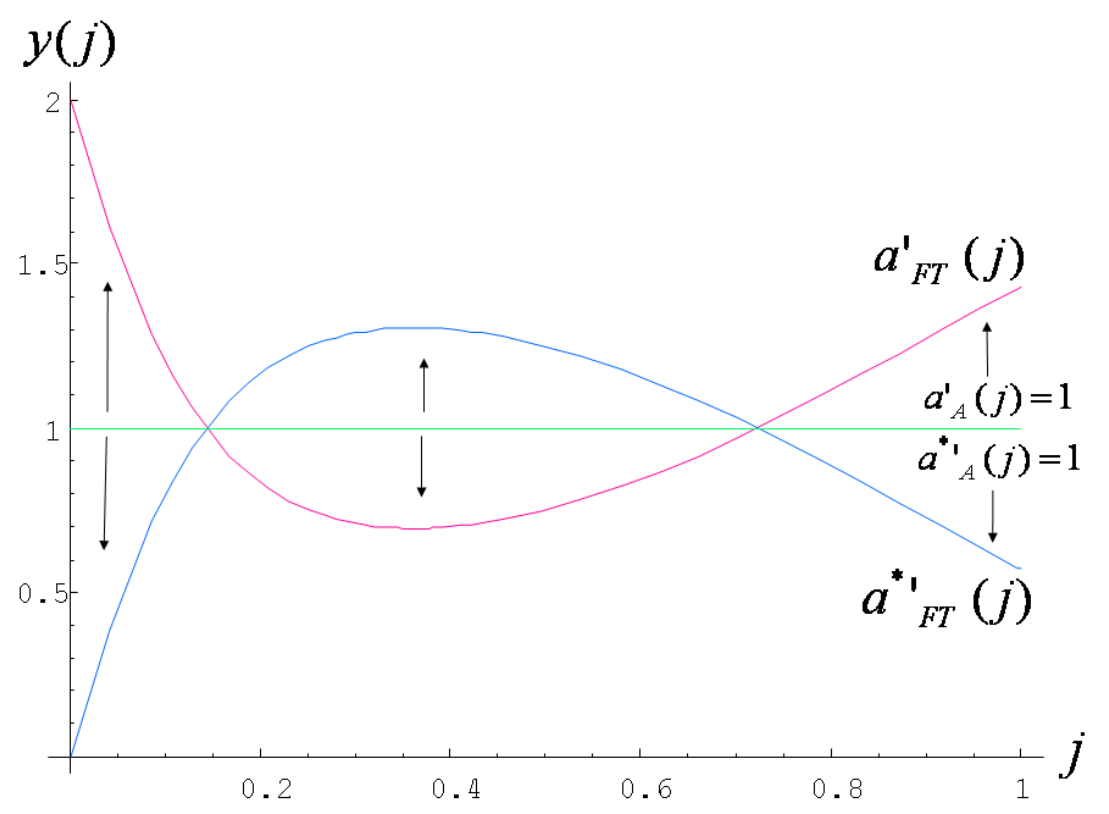

Figure 5: Employment Density by Sector: Autarky and Free Trade. 
In addition to the employment and skill acquisition effects of trade liberalization, we are of course keenly interested in the welfare implications of freer trade. In what follows we first focus on Home before turning to Foreign. The real welfare change consists of two parts: the effect of trade liberalization on real wages and the shift in the realized costs of education. We take each part in turn, showing first the real wage effects, then the changing costs of equilibrium educational attainment, and finally the net welfare effects by ability type.

Using the zero profit condition for final goods production, ${ }^{24}$ we find that the equilibrium real wage in a given sector $\hat{j}$ is given by $w_{0}+\int_{0}^{\hat{j}} \dot{w}(j) d j$, where the base wage in sector $j=0$ is determined by $w_{0} \equiv 1-\int_{0}^{1} \dot{w}(j) d j$. Solving yields the two panels in Figure 6, which depict respectively the change in the real wage in sector $j$ following trade liberalization, and the change in the real wage of agent a given her optimal sectoral choice under each trading regime.

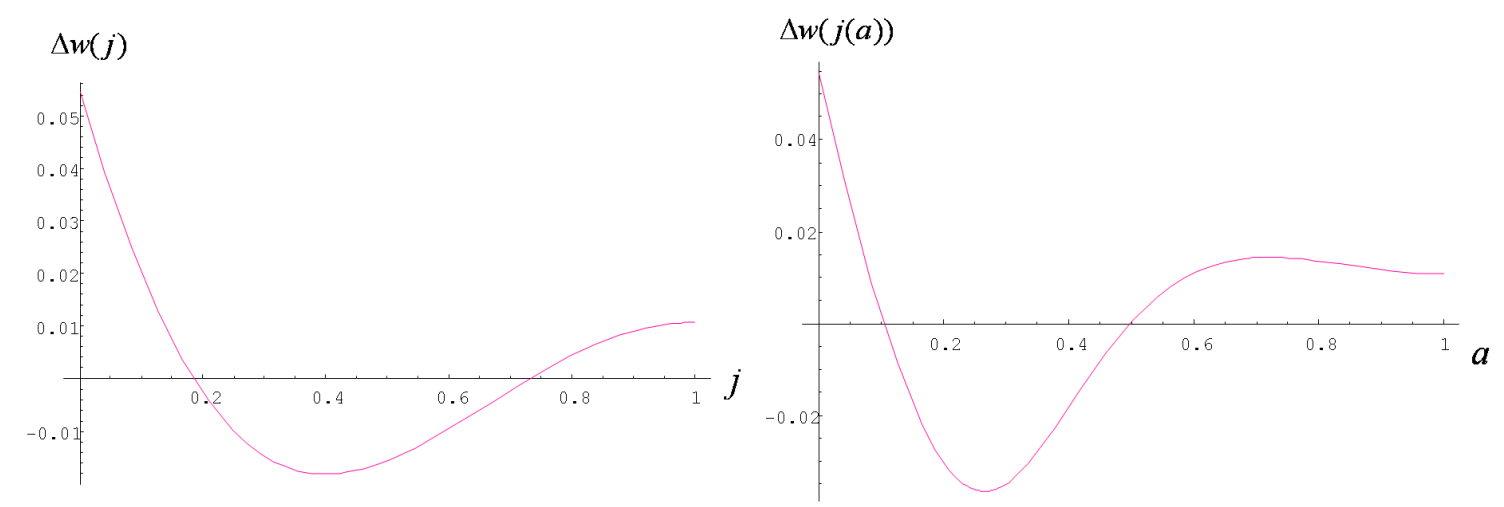

Figure 6: Effect of Trade on Wages at Home.

From the first panel in Figure 6, we see that real wages rise for the low and high $j$ sectors, and fall for intermediate sectors (roughly $j \in[.2, .7]$ ) Again, we see that the equilibrium prediction for Home - this time measured in real wage changes rather

\footnotetext{
${ }^{24}$ Under the Leontief production structure and choice of $Y$ as numeraire, zero profit implies $1=$ $\int_{0}^{1} w(j) d j$.
} 
than employment - is broadly consistent with empirical evidence: recall the U.S. wage polarization demonstrated by Autor, Katz, and Kearney (2006). The second panel takes into account the induced occupational shift, confirming that the change in realized real wages is non-monotonic across workers: agents with low ability earn higher real wages under trade, agents with high ability do as well, and agents in the lower-middle portion of the ability distribution see their real wages fall.

Figure 7 shows the change in the real cost of education across workers. Remembering that agents in the lower forty percent of the ability distribution optimally sort down while agents in the upper part of the distribution choose to sort up, it is obvious that the real cost of education should decrease for the left portion of the distribution and increase for the right.

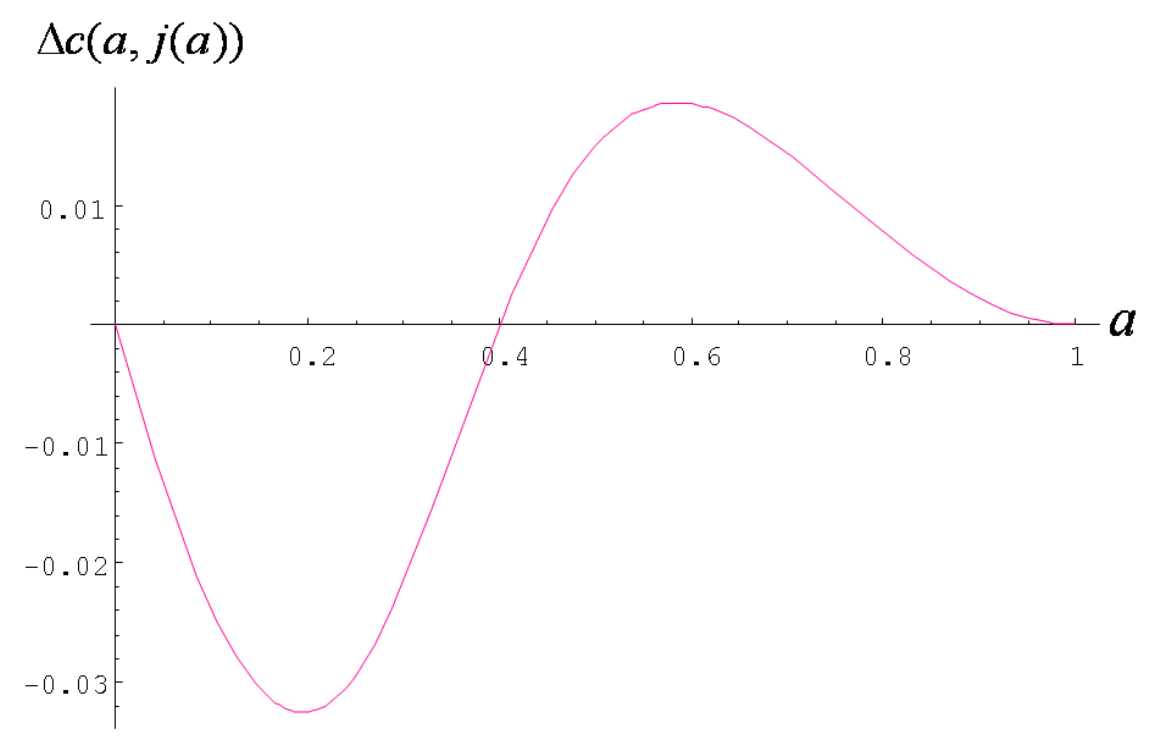

Figure 7: Change in the Home Real Cost of Education across Workers

Figure 8 shows the net welfare change for Home's population. Combined with the effect on the real wage, the adjustment for the changing cost of education has shifted the identity of the 'biggest loser' to the right. Indeed, consider the plight of the 
agent $a=.6$. Although her real wage has increased, the increased cost of education required to achieve the higher paying job more than offsets the wage gain so that the net welfare change is negative. Conversely, agent $a=.2$ suffers a substantial real wage loss yet enjoys a modest net welfare improvement due to his now lower cost of education. A crucial caveat to this second statement is that lower costs of education cannot be recovered if they are sunk. In a dynamic framework with unanticipated trade shocks, we therefore would expect to see the burden of increased costs of (potentially mid-career) education manifest in net welfare changes, while education savings would not be realized for the older generations.

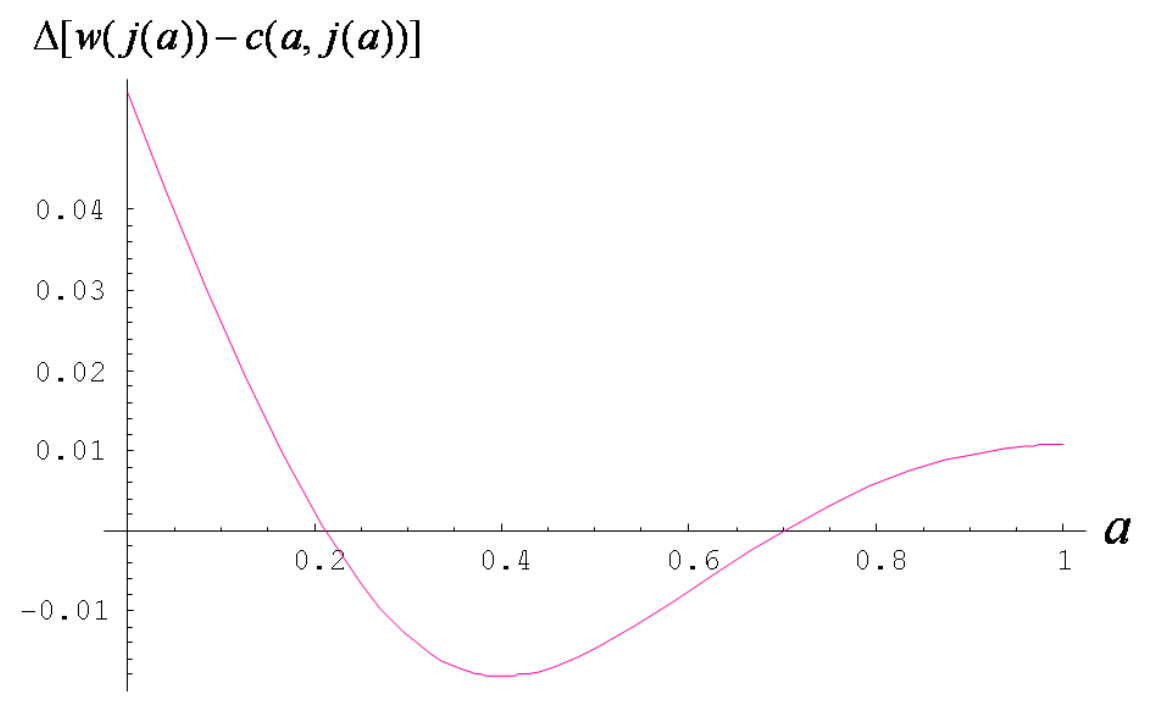

Figure 8: Net Welfare Effect of Trade in the Home Country.

Turning now to the Foreign country, we find that the net welfare effects are a mirror image of what happens at home. In contrast to Home, the real wage increases most for Foreign agents in the middle of the income distribution while falling at the distribution extremes. At the same time, the cost of education rises for the lower forty percent of the distribution of workers and falls for the remainder. The net welfare 
effect of trade is shown in the final panel of Figure 9, where we see that middle ability agents gain from trade, while the highest and lowest ends of the population distribution lose.

To summarize the results from this general equilibrium example, we depict both the Home and Foreign net welfare changes by worker in Figure 9. While in the Home country it is the medium ability agents who suffer, their Foreign counterparts are the main beneficiaries of trade liberalization, together with high and low ability agents at Home. Integrating the net real effects in each country confirms that there are positive gains from trade for both countries.

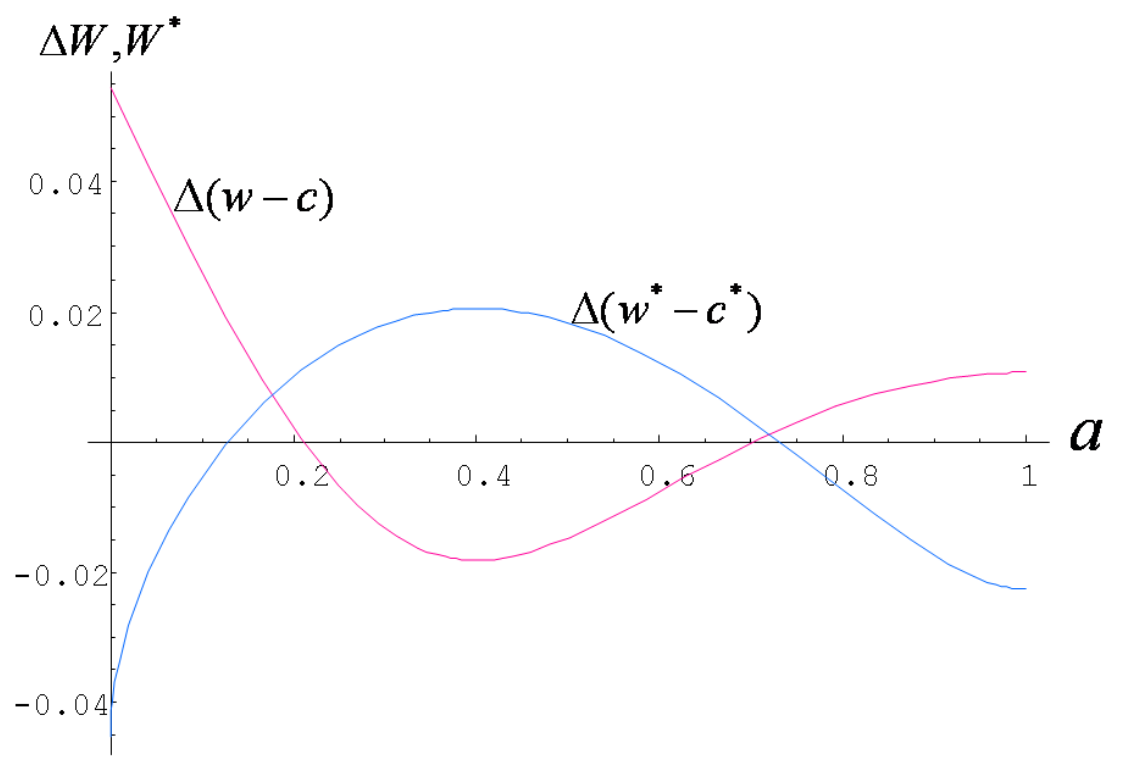

Figure 9: Opposing Individual Welfare Effect of Trade in Home and Foreign.

Finally, before continuing, let us reiterate that these graphs are generated under a specific set of assumptions, which we chose intentionally chosen to generate the "vacating middle" phenomenon. Alternative functional form assumptions (particularly over the relative convexity of the foreign and home education cost structures, but also in demand or final goods technology), naturally would deliver different pre- 
dictions for comparative advantage and thus the effect of trade on skill acquisition, the distribution of income, and welfare. Nonetheless, we find that working through a particular closed form example with simple graphical results, proves to be a useful exercise for understanding the underlying mechanisms in the general framework.

\section{Policy Implications}

Our model immediately suggests itself to policy analysis, as indeed was our initial intention. In the next section, we focus on the potential role of educational policy and trade protection in shaping the distribution of income and human capital, and note in particular the extent to which the two policy instruments are complementary.

\subsection{Educational Policy}

In practice, educational policy takes many forms. Broadly speaking, educational initiatives can increase educational productivity (for instance, by reducing institutional overhead, through curriculum reform, or by expanding teacher education and incentives), decrease the costs of education borne by students, or both. Here, we focus on the latter as it is simpler from a modelling perspective and isomorphic in its underlying implication for human capital decisions. ${ }^{25}$ We define an educational subsidy, $s(j)$, as a means to help individuals acquiring education in a given sector/task $j$ shoulder the monetary cost of doing so, $c(j, a)$. By assumption, the subsidy can vary by type of education or skill level to be acquired, but cannot be conditioned on the unobservable inherent ability level of the agent, which is private information. In order to balance the government's budget, we assume that the subsidies are financed by a poll tax.

\footnotetext{
${ }^{25}$ Specifically, increasing education productivity would have the same (positive) effect on individuals' skill acquisition decisions as reducing the cost of education, but the former would simultaneously increase worker productivity (conditional on education level) while the latter would not.
} 
Recall the first order condition of the educational choice problem derived earlier in (2.5). Introducing an educational subsidy leads to the following augmented first order condition:

$$
\dot{c}(j, a)-\dot{s}(j)=\dot{w}(j),
$$

where $\dot{s}(j)$ is the first derivative of the subsidy function with respect to $j$ (assuming $s(\cdot)$ is differentiable). We assume that the educational subsidy function is such that the left hand side of the augmented first order condition in (4.1) satisfies the derivative property assumptions (convexity, single crossing) we made regarding the educational cost function in (2.1).

For the following result, we adopt the small country assumption to rule out any effects on the world price schedule. Moreover, we continue to assume a 'nice' case in which both before and after the introduction of the educational subsidy, the second order condition for each agents' optimal skill acquisition decision is satisfied globally, so that the derivative cost schedule crosses the derivative wage schedule at most once from below. The following proposition then follows directly from the augmented first order condition in (4.1):

Proposition 4.1 If $c(j, a)+s(j)$ satisfies properties analogous to (2.1), then for all $j \in(0,1)$ the educational subsidy schedule $s(j)$ has the following (local) effects:

i) if $\dot{s}(j)=0$ then $a(j, \vec{s})=a(j, \vec{s}=0)$;

ii) if $\dot{s}(j)>0$ then $a(j, \vec{s}) \leq a(j, \vec{s}=0)$;

iii) if $\dot{s}(j)<0$ then $a(j, \vec{s}) \geq a(j, \vec{s}=0)$.

The first part of the proposition implies that a uniform subsidy would not affect individuals' educational choices; rather, it is the marginal cost of additional education 
that matters. ${ }^{26}$ Parts $\left.i i\right)$ and $\left.i i i\right)$ imply that if the subsidy scheme is uniformly progressive (regressive) - offering higher subsidies at lower (higher) education levels so that $\dot{s}<0(>0)$ across the board- then all agents would sort monotonically into higher (lower) skilled occupations. More generally, the local effect of a subsidy change on agents initially located in a particular sector $j$ would be to induce educational upgrading (downgrading) if the net marginal cost of education is decreased (increased) by the subsidy scheme.

Now consider the following: how might the government use educational policy to soften the impact of globalization ${ }^{27}$ The negative impact of trade - at least in the example discussed earlier — is felt by middle-ability agents. If the government, perhaps in the interest of political stability that relies on a sizable middle class, wants to counteract the 'vanishing middle class' phenomenon, it has to provide an educational subsidy schedule that features a positive slope for low ability agents and a negative (or at least much flatter) slope for higher ability agents. In other words, it has to channel educational subsidies towards mid-level skill acquisition. The German educational system and the country's strong middle class can be regarded as anecdotal evidence for such an approach. In contrast, educational tax credits, which are roughly proportional to the cost of education, are regressive in the sense that they provide little to no (additional) subsidy through the secondary school level, and offer increasing subsidies thereafter. ${ }^{28}$

Notice that targeted education subsidies toward middle class workers effectively constitute a production subsidy to import-competing sectors. From an efficiency

\footnotetext{
${ }^{26}$ This finding is little surprise as a uniform subsidy to agents in all sectors simply cancels the poll tax (given full employment and positive education subsidies for all sectors $j \in[0,1]$ ).

${ }^{27}$ This is not to say that we advocate such an objective from an efficiency point of view; rather, we simply explore the possibility as one that seems consistent with many politicians' stated goals.

${ }^{28}$ Although per-annum education credits are generally capped (making the effective subsidy uniform for sufficiently high tuition levels in a given year), the lifetime educational tax credit is clearly proportional to years of schooling, and thus (generally) increasing with skill acquisition.
} 
point of view, such a policy is clearly counter-productive, as redistribution could be more efficiently achieved through more direct means. If, however, the country is large enough to influence the world market price schedule, then targeted middle class education subsidies would also improve the terms-of-trade and thereby shift part of the efficiency cost of middle class education subsidies onto foreign competitors. That said, a favorable shift in the terms-of-trade can be more efficiently achieved by trade policy than through educational subsidies, as we discuss in the next sub-section.

\subsection{Trade Policy}

We offer a brief positive analysis of how trade policy influences educational choices, before turning to the normative question of optimal instrument choice. Let us initially adopt the small country assumption and define the specific tariff/export subsidy for good $j$ by $t(j)$, so that the net domestic price/wage is now given by $w^{d}(j) \equiv w(j)+$ $t(j)$, where $w(j)$ denotes the world price of good/task $j$.

On the supply side, the effect of a specific tariff (export subsidy) on human capital decisions is virtually identical to that of an educational subsidy. This is readily apparent from the augmented first order condition of the individuals' educational decision, which now takes the form:

$$
\dot{c}(j, a)=\dot{w}(j)+\dot{t}(j)
$$

where $\dot{t}(j)$ is the derivative of the trade tax/subsidy schedule with respect to $j$, and we assume that $c(j, a)-t(j)$ satisfies properties analogous to (2.1). As with the education subsidy, a uniform trade tax schedule across all tasks will have no effect on agents' human capital decisions. ${ }^{29}$ If the trade tax/subsidy schedule exhibits positive or negative slope, on the other hand, then it affects the individuals' skill acquisition

\footnotetext{
${ }^{29}$ An ad-valorem tax/subsidy schedule would have an effect, of course, as its specific equivalent would imply a higher net wage derivative schedule for more skilled (higher wage) sectors.
} 
decision: a positive (negative) slope induces individuals to choose a higher (lower) type of education. ${ }^{30}$

Now let us suppose that a policymaker seeks to mitigate the impact of globalization on the middle class by using tariffs. To be consistent with commonly observed policy measures and WTO rules, we consider the effect of imposing tariffs only on imported goods, without introducing trade policy on the export side. In particular, we consider import tariffs that are chosen in such a way as to 'close the lens' between the autarkic and the free trade wage schedules, as is shown in panel A of Figure 4.2. Clearly, these tariffs also affect the derivative wage schedule. Jumps occur at the thresholds $j^{*}$ and $j^{* *}$, that separate exported from imported intermediates, as depicted in Panel B of Figure 4.2. These discontinuities in the derivative wage schedule induce two 'empty' regions, as agents on the left side of those regions sort down and those on the right side sort up. ${ }^{31}$ These 'empty' sectors have no domestic employment, and are thus Ricardian-like regions in which the Foreign country would be the sole producer worldwide, in line with the Dornbusch, Fischer, and Samuelson (1977) framework. Substantial levels of tariff protection could thus have the (unintended) consequence of dismantling some previously export-competing industries just below and above the lower and upper discontinuities.

It is clear that import protection will shelter the middle class from global competition in mid-range sectors, and may thus serve a policymaker's goal of influencing human capital decisions and the pattern of employment in the desired way. At the same time, however, tariffs also impose demand-side distortions that targeted edu-

\footnotetext{
${ }^{30}$ Given the immediate parallel with the case of an educational subsidy (which subtracts $\dot{s}(j)$ from the left hand side of the agents' first order condition rather than adding $\dot{t}(j)$ to the right hand side), we omit restating the results as a formal proposition. Simply note that the trade tax/subsidy result can be read directly from Proposition 4.1 replacing $s(j)$ with $t(j)$.

${ }^{31}$ The extent to which this happens clearly depends on the height of the jumps which is determined by the tariff schedule.
} 

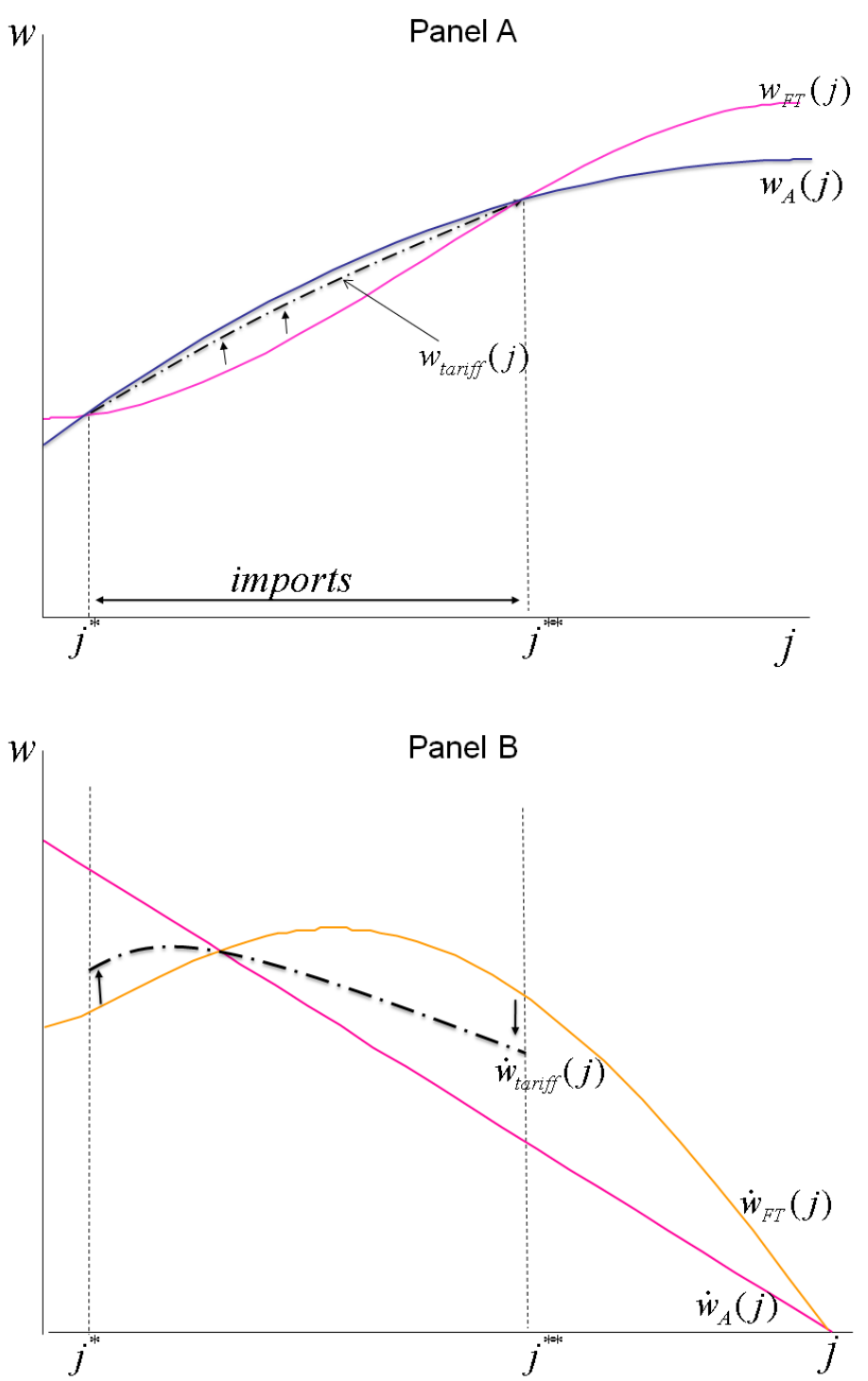

Figure 10: Effects of an import tariff

cational subsidies would not. ${ }^{32}$ If the country is large, this demand-side distortion will improve the terms-of-trade (by decreasing world relative demand for mid-range goods), whereas for a small country, any demand-side distortion constitutes a pure

\footnotetext{
${ }^{32}$ The exception is the case of Leontief final good production, which entails no distortion. However, this is clearly a special case and unique to the Leontief functional form assumption.
} 
efficiency loss.

\subsection{Instrument Choice}

Moving to a normative comparison of different policy instruments, it is clear that the first best policy instrument depends on the government's underlying objective. If the government wants to shift the distribution of income, then of course lump sum taxes are the first best policy choice; if instead the goal is to shift the distribution of human capital, then educational subsidies (or taxes) are most efficient; and if the government simply seeks to manipulate the terms of trade, then of course trade policy remains the best means to achieve that end. Summarizing another way, education subsidies constitute a first best policy for shifting the distribution of human capital, a second best policy for shifting income (which is more efficiency achieved through direct redistribution and lump sum taxation), and a third best policy for manipulating world prices (which is better done via import tariffs). Trade taxes/subsidies, on the other hand, are first best for manipulating the terms of trade, second best for manipulating educational decisions (which is better achieved through education policy), and worst for shifting the distribution of income. Regrettably, political rhetoric rarely seems to square with these efficiency rankings across policy instruments.

\section{Conclusion}

In this paper we develop a model of trade and education that allows for differentiated effects of trade liberalization on skill acquisition. Agents of different ability levels selfselect into sectors by acquiring the specific education necessary to work in a particular sector, or to perform a particular task. This mapping of ability level to sectors depends on the wage or price schedule and hence on a country's openness to trade. We show how changes in the price schedule affect this mapping and lead agents to sort up and 
down simultaneously. If a country's educational cost structure is less convex than that of its trading partners, then low ability agents sort down and higher ability agents sort up, and we obtain a 'vacating of the middle' with corresponding negative welfare effects for the middle class. This result provides one possible explanation for the current public concern over the negative effects of globalization for 'average' workers.

Our framework can shed light on the potential differential impacts of strengthening educational institutions. Government subsidies to education or similar institutional improvements that decrease the cost of skill acquisition over some ranges of sectors or for certain agents would impact the distribution of human capital decisions and thus the pattern of trade and comparative advantage, aggregate social welfare, and intra-national income distribution. In more general terms, the model developed here provides a novel reason for trade. By abstracting from differences in technology or preferences, we show how differences in educational institutions endogenously give rise to comparative advantage and hence trade.

Going forward, our model provides a novel framework with which to analyze the aggregate effects of targeted educational policies at the primary, secondary, or tertiary levels. Uniform 'across the board' subsidies to education are unlikely to even the distribution of human capital within a country; perhaps highly focussed educational policies such as Brazil's are not as ill founded as some have suggested. Our model is similarly well suited to study the effects of educational migration, including the increased graduate attainment in the U.S. by foreign born students recently documented in Blanchard, Bound, and Turner (2008). Finally, In a somewhat more technical extension, one could explore systematically the nature of the interaction of technological changes with trade and education, in an effort to inform an empirical strategy for identifying the welfare effects of trade apart from technological innovation, while explicitly recognizing the endogeneity of worker's human capital decisions. 
REFERENCES

\section{References}

Anderson, J. (2011). The specific factors continuum model, with implications for globalization and income risk. Journal of International Economics 85, 174-185.

Antras, P., L. Garicano, and E. Rossi-Hansberg (2006). Offshoring in a knowledge economy. Quarterly Review of Economics 121(1), 31-77.

Autor, D. and D. Dorn (2013). The growth of low-skill service jobs and the polarization of the u.s. labor market. American Economic Review (forthcoming).

Autor, D., L. Katz, and M. Kearney (2006). The polarization of the u.s. labor market. American Economic Review Papers and Proceedings 96(2), 189-194.

Autor, D., F. Levy, and R. Murnane (2003). The skill content of recent technological change: an empirical exploration. Quarterly Journal of Economics 58, 1279333.

Berman, E., J. Bound, and Z. Griliches (1999). Changes in the demand for skilled labor within u.s. manufacturing: Evidence from the annual survey of manufactures. Quarterly Journal of Economics 109(2), 237-97.

Blanchard, E., J. Bound, and S. Turner (2008). Opening (and closing) doors: Country specific shocks in u.s. doctorate education. In R. Ehrenberg and C. Kuhn (Eds.), Doctoral Education and the Faculty of the Future. Cornell University Press (forthcoming).

Bound, J. and G. Johnson (1992). Chages in the structure of wages in the 1980s: An evaluation of alternative explanations. American Economic Review 82(3), $371-92$.

Broda, C. and J. Romalis (2009). The welfare implications of rising price dispersion. mimeo.

Card, D. and T. Lemiuex (1996). Wage dispersion, returns to skill, and black-white wage differentials. Journal of Econometrics 74, 319-61. 
Costinot, A. and J. Vogel (2010). Matching and inequality in the world economy. Journal of Political Economy 118(4), 747-786.

Dornbusch, R., S. Fischer, and P. Samuelson (1977). Comparative advantage, trade, and payments in a ricardian model with a continuum of goods. American Economic Review 67(5), 823-839.

Falvay, R., D. Greenaway, and J. Silva (2010). Trade liberalization and human capital adjustment. Journal of International Economics 82(2), 230-239.

Goos, M. and A. Manning (2007). Lousy and lovely jobs: The rising polarization of work in britain. Review of Economics and Statistics 89, 118-33.

Grossman, G. and G. Maggi (2000). Diversity and trade. American Economic Review $90(5), 1255-1275$.

Grossman, G. and E. Rossi-Hansberg (2008). Trading tasks: A simple theory of offshoring. American Economic Review 98(5), 1978-1997.

Helpman, E., O. Isthoki, and S. Redding (2010). Inequality and unemployment in a global economy. Econometrica 78(4), 1239-1283.

Juhn, C., K. Murphy, and B. Pierce (1993). Wage inequality and the rise in returns to skill. Journal of Political Economy 101(3), 410- 442.

Jung, J. and J. Mercenier (2008). A simple model of offshore outsourcing, technology upgrading and welfare. Mimeo.

Katz, L. and K. Murphy (1992). Changes in relative wages, 1963-1987: Supply and demand factors. Quarterly Journal of Economics 107(1), 35-78.

Milgrom, P. and J. Roberts (1990). The economics of modern manufacturing: Technology, strategy, and organization. American Economic Review 80(3), 511-28.

Mrazova, M. and J. P. Neary (2012). Selection effects with heterogeneous firms. Oxford University Mimeo. 
Nocke, V. and S. Yeaple (2008). An assignment theory of foreign direct investment. Review of Economic Studies 75(2), 529-57.

Ohnsorge, F. and D. Trefler (2007). Sorting it out: International trade with heterogeneous workers. Journal of Political Economy 115(5), 868-892.

Pew Research Center (2012). Fewer, poorer, gloomier: A lost decade for the middle class. Technical report. August 22, 2012; www.pewsocialtrends.com.

Ravallion, M. (2009). The developing world's bulging (but vulnerable) "middle class". World Bank Policy Research Working Paper no. 4816.

Yeaple, S. R. (2005). A simple model of firm heterogeneity, international trade, and wages. The Journal of International Economics 65, 1-20.

\section{A1 Appendix}

\section{A1.1 Proof of Lemma 2.1}

1. Taking the derivative of $a(j)$ with respect to $j$ yields: ${ }^{33}$

$$
a^{\prime}(j)=\frac{1}{h^{\prime}\left(\frac{\dot{w}}{\dot{g}}\right)}\left[\frac{\ddot{w} \dot{g}-\dot{w} \ddot{g}}{\dot{g}^{2}}\right] .
$$

Substituting from the first order condition in (2.5):

$$
a^{\prime}(j)=\frac{1}{h^{\prime}\left(\frac{\dot{w}}{\dot{g}}\right)}\left[\frac{\ddot{w} \dot{g}-h(a) \dot{g} \ddot{g}}{\dot{g}^{2}}\right] .
$$

Then, from the definition of the cost function:

$$
a^{\prime}(j)=\frac{1}{h^{\prime}\left(\frac{\dot{w}}{\dot{g}}\right)}\left[\frac{\dot{g}(\ddot{w}-\ddot{c})}{\dot{g}^{2}}\right] \geq 0,
$$

using the second order condition $(\ddot{c} \geq \ddot{w})$ and the assumptions on the cost function in (2.1), which imply that $\dot{g}>0$ and $h^{\prime}(x)<0$ iff $x>0$. By assumption,

\footnotetext{
${ }^{33} \mathrm{An}$ alternate proof may be derived by taking the total derivative of the first order condition in (2.5), with respect to $j$ and $a$, rearranging, then noting that under the second order condition (that $\ddot{w}(j) \leq \ddot{c}(j), a^{\prime}(j) \geq 0$ if and only if $\frac{\partial c(j, a)}{\partial j \partial a}<0$ (i.e. if $a$ and $j$ are sub modular in $c(\cdot)$ ), as assumed.
} 
$\dot{w} \geq 0 \forall j$, so

$$
a^{\prime}(j)=\underbrace{\frac{1}{h^{\prime}\left(\frac{\dot{w}}{\dot{g}}\right)}}_{(-)}\left[\frac{\dot{g}(\ddot{w}-\ddot{c})}{\dot{g}^{2}}\right]>0 \Longleftrightarrow \ddot{c}>\ddot{w} . \diamond
$$

2. From the definition of $a(j)$ :

$$
a(j)=h^{-1}\left(\frac{\dot{w}}{\dot{g}}\right) .
$$

Both $g(\cdot)$ and $h(\cdot)$ are twice continuously differentiable and invertible by assumption. Thus, $a(j)$ is continuous in $j$ if $\dot{w}(j)$ is continuous (i.e. $w(j) \in C^{1}$ ). Moreover, $a(j)$ is continuously differentiable in $j$ if $\ddot{w}(j)$ is continuous (i.e. $\left.w(j) \in C^{2}\right)$.

3. From part (1) above:

$$
a^{\prime}(j)=\frac{1}{h^{\prime}\left(\frac{\dot{w}}{\dot{g}}\right)}\left[\frac{\ddot{w} \dot{g}-\dot{w} \ddot{g}}{\dot{g}^{2}}\right] .
$$

Again from our earlier assumptions, $h^{\prime}(\cdot), \dot{g}$, and $\ddot{g}$ are finite, and $\dot{g}>0$. Thus, $a^{\prime}(j)<\infty$ if and only if $\ddot{w} \dot{g}-\dot{w} \ddot{g}<\infty$. A sufficient condition is $w(j) \in C^{2}$, as stated in the lemma.

\section{A1.2 GE Example Extension: Limited Diversification}

In the baseline example, every task is carried out in both countries in equilibrium; that is, even under free trade, the production of intermediates remains fully diversified across the entire range of occupations. This needn't hold in general. We now present a modified case where trade induces one trading partner to stop production of a particular subset of intermediates, a phenomenon that is certainly relevant in reality, where for example certain inputs can be sourced locally only at very high cost. Suppose the educational costs take the following (slightly modified) form

$$
\begin{aligned}
c[j, a] & =\frac{1}{a} * \frac{j^{2}}{2} \\
c^{*}[j, a] & =\frac{1}{a} * \frac{2 j^{3}}{3}
\end{aligned}
$$


and assume the same production technology for the final good as before. We can solve for the autarky and free trade equilibrium wage schedules:

$$
\begin{aligned}
\dot{w}_{A} & =1 \\
\dot{w}_{A}^{*} & =2 j, \\
\dot{w}_{F T} & = \begin{cases}\frac{j+2 j^{2}}{2 j} & j<\frac{1}{4}(1+\sqrt{5}) \\
\frac{j}{2 j-1} & j \geq \frac{1}{4}(1+\sqrt{5})\end{cases}
\end{aligned}
$$

These are graphically depicted in Figure 11. Note that the free trade equilibrium slope of the wage schedule (sandwiched between the autarky schedules) consists of two parts: up to $j=\frac{1}{4}(1+\sqrt{5}) \equiv \bar{j}$ both countries produce each task, whereas above only the home country does. This is because at the upper bound $(j=1)$ the marginal costs of education for the most able agents in both countries differ: the domestic agent with $a=1$ only has half as high a marginal cost as the foreign agent, $a^{*}=1$. Hence in equilibrium, the most able foreign agent does not find it worthwhile to acquire the sophisticated skills necessary to carry out the most sophisticated task. Instead she chooses $\bar{j}<1 .{ }^{34}$

As before, graphing the ability-to-task mappings under autarky and free trade in Figure 12 indicates how trade liberalization affects the skill acquisition decisions: to the left of the intersection agents at home sort down, whereas higher ability agents sort up and acquire more sophisticated skills, and the opposite happens in the foreign country. Thus the result that domestic agents vacate the middle obtains here as well.

Finally, comparing the wage change and the change in the cost of education gives the welfare effects depicted in Figure 13. Again we see that the middle ability agents at home lose out whereas agents at the bottom and top benefit from trade,

\footnotetext{
${ }^{34}$ We find this threshold by using the boundary condition $\dot{c}(a=1, j=1)=\dot{w}$ to determine the constant of integration of the w-dot schedule that equates home supply to world demand. Since 'smooth pasting' of the wage schedules for the upper and lower ranges implies the same derivative at the threshold, we find the threshold by plugging $a^{*}=1$ into the 'only home production' schedule already determined. 'Smooth pasting' then pins down the constant of integration of the schedule to the left where both countries produce.
} 


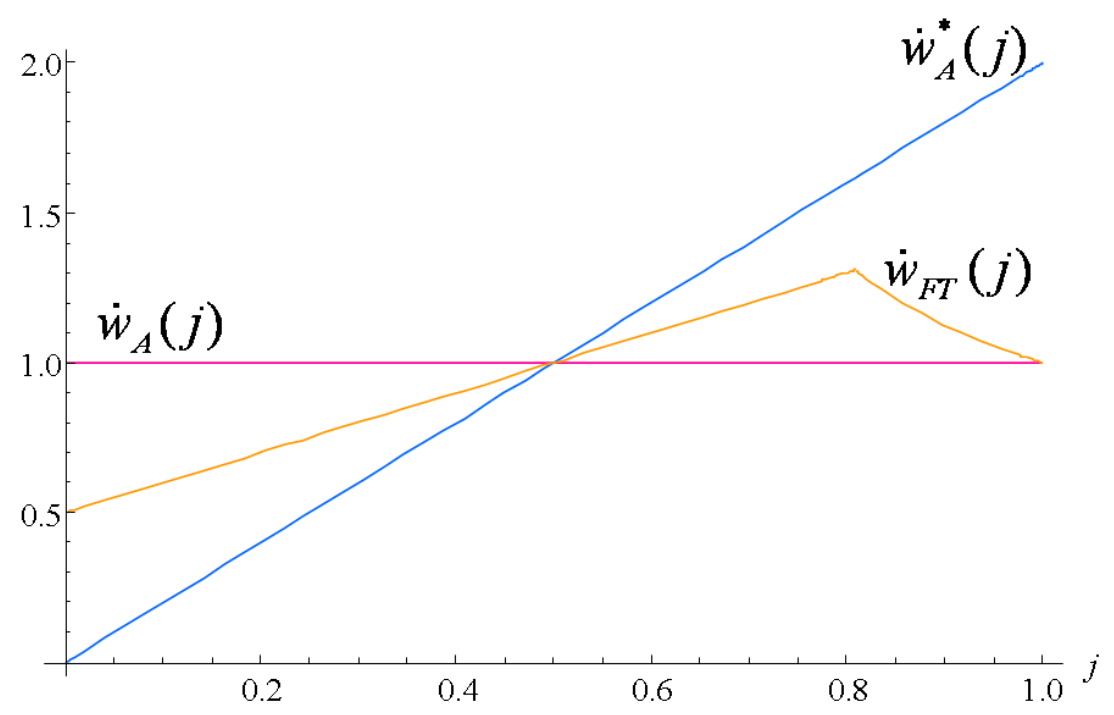

Figure 11: Wage schedules under autarky and free trade.

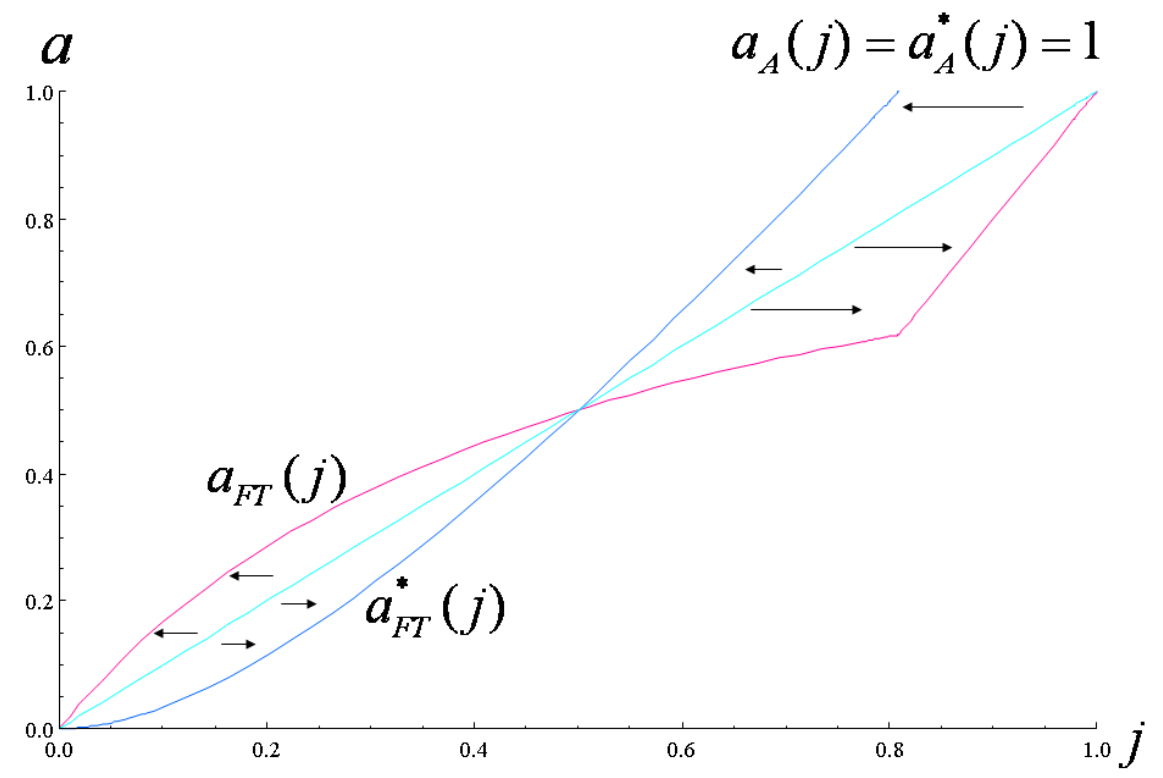

Figure 12: Ability-sector mappings under autarky and free trade. 


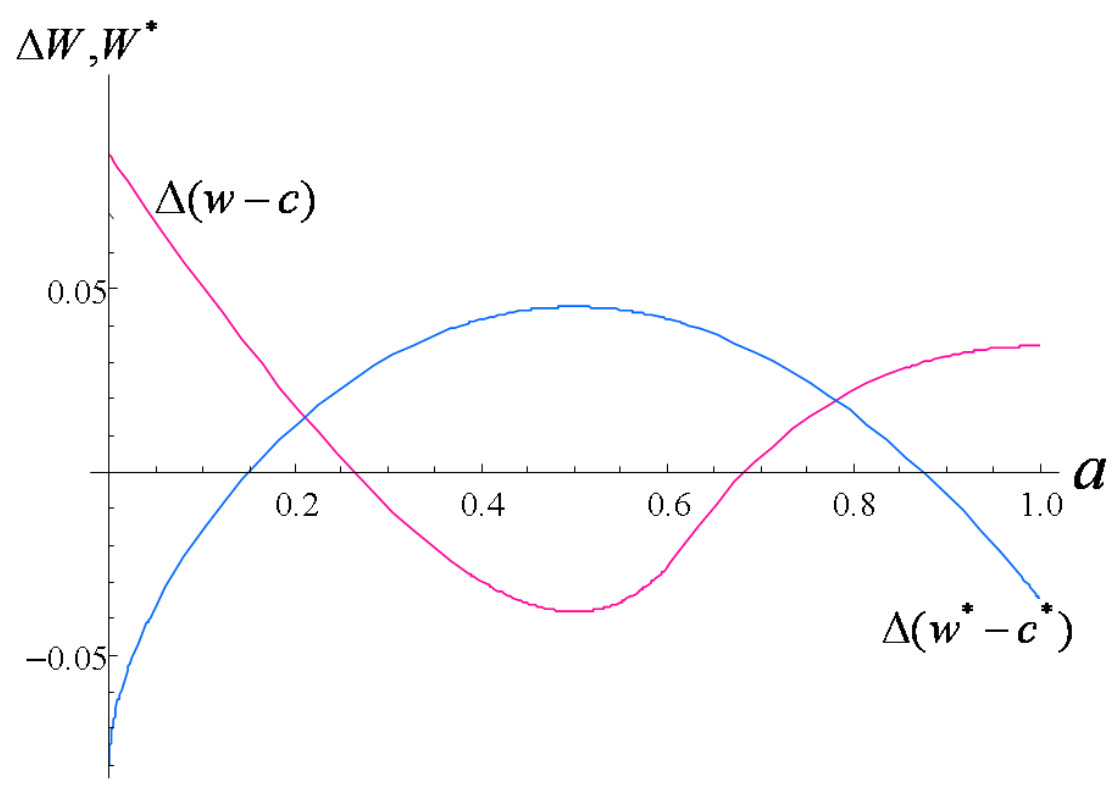

Figure 13: Net Welfare Effect of Trade in the Home Country.

and the welfare effects in the foreign country are the opposite. We have therefore confirmed that our previous result is robust to the possibility that countries restrict the range of tasks they produce in response to trade liberalization. 